\title{
Attitudes of Academic Staff and Students towards the Objective Structured Clinical Examination (OSCE) in Obstetrics and Gynaecology
}

\author{
Alexander Emeakpor Omu1,2, Majedah Komaikh Al-Azemi',2, Florence Emadinwe 0mu3 \\ Jehad Al-Harmi ${ }^{1}$, Michael Fidelis Esiekpe Diejomaoh ${ }^{1,2}$ \\ ${ }^{1}$ Departments of Obstetrics and Gynaecology, Faculty of Medicine, Health Sciences Centre, Kuwait University, \\ Kuwait City, Kuwait \\ ${ }^{2}$ Maternity Hospital, Kuwait City, Kuwait \\ ${ }^{3}$ College of Nursing, Public Authority for Advanced Education and Training (PAET), Adailiyah, Kuwait \\ Email: Omu@hsc.edu.kw
}

Received 5 April 2016; accepted 16 May 2016; published 19 May 2016

Copyright (C) 2016 by authors and Scientific Research Publishing Inc.

This work is licensed under the Creative Commons Attribution International License (CC BY). http://creativecommons.org/licenses/by/4.0/

(c) (i) Open Access

\begin{abstract}
Introduction: The Department of Obstetrics and Gynaecology first implemented the Objective Structured Clinical Examination (OSCE) in the final examinations in 2003 academic year to replace the long case and oral examination on short cases and to evaluate the attitude of staff and medical students towards OSCE as a method of clinical assessment. Methods: Three main groups were evaluated: 1) 96 medical students at their final examination in Obstetrics and Gynaecology and were assessed with OSCE; 2) 30 Kuwait trained doctors who were assessed with OSCE during their undergraduate training; 3 ) academic staff made up internal faculty staff (12) and external examiners. Results: Perception of examination was highly positive among the students: Quality of instruction and organization $(96 \%)$, transparency of the process $(96 \%)$, method of assessing clinical skills $(90 \%)$, patients' care (89\%), assessment of knowledge $(84 \%)$ and communication skills (84\%). Significantly, more of the trainee doctors that had OSCE during their training (92\%) had positive perception of OSCE than those trainees $(65 \%)$ that did not $(P<0.05)$. Both the internal and external examiners had an equally high perception of OSCE $(83 \%$ versus $92 \% ; P=0.85)$, citing less examiner fatigue and more enjoyable for examiners and students. Conclusion: OSCE may be a more appropriate choice for graduation examinations of compared to the conventional clinical examination. It is expensive in terms of manpower requirement. There should be continuing research to reduce stress to students and examiners.
\end{abstract}

\section{Keywords}

Academic Staff, Medical Students, Attitude, Perception, Objective Structured Clinical Examination

How to cite this paper: Omu, A. E., Al-Azemi, M. K., Omu, F. E., Al-Harmi, J., \& Diejomaoh, M. F. E. (2016). Attitudes of Academic Staff and Students towards the Objective Structured Clinical Examination (OSCE) in Obstetrics and Gynaecology. Creative Education, 7, 886-897. http://dx.doi.org/10.4236/ce.2016.76093 


\section{Introduction}

The traditional clinical examination, consisting of long cases, short cases and vivas, has some strengths but unfortunately significant limitations in terms of validity and reliability (Wallace, Rao, \& Haslam, 2002). The advent of the structured performance tests has enabled some of the limitations to be overcome. The objective structured clinical examination (OSCE) was first described by Harden \& Gleeson as, "a timed examination in which medical students interact with a series of simulated patients in stations that may involve history-taking, physical examination, counselling or patient management” (Harden et al., 1975).

\subsection{OSCE in Undergraduate Medical Education}

The use of OSCEs in undergraduate examinations was thereafter, pioneered by the Royal London and St. Bartholomew's Hospitals and now occurs in every London medical college. Many colleges across the UK have now adapted their examinations to include OSCE components. In many disciplines and specialities, OSCEs have been studied extensively and their reliability and validity established. Because OSCEs have been shown to be feasible and have good reliability and validity (Hodges et al., 1998). Their use has become widespread as the standard for performance-based assessment, particularly in undergraduate examinations. The Objective Structured Clinical Examination (OSCE), as a measure of clinical competence that focuses on outcomes via observable behaviours, is gaining international recognition (Carraccio \& Englander, 2000).

\subsection{Traditional Clinical Examination versus OSCE}

With the increasing difficulties in the recruitment of patients for the traditional clinical examination, several of the Medical Royal Colleges have introduced an OSCE component into their postgraduate membership examinations. For example, the Royal College of Anaesthetists includes an OSCE in Part I of the fellowship examination, and the Royal College of Obstetricians and Gynaecologists has an OSCE in Part II of their examinations. The Royal College of Surgeons, London, is also introducing OSCEs. The Royal College of Physicians has a Practical Assessment of Clinical Examination Skills (PACES) in their clinical examinations, part of which comprises a communication and ethics station, in which simulated patients are used (Grand'Maison, Blouin, \& Briere 1985).

\subsection{Conceptual Boundaries of OSCE}

The OSCE has been used to evaluate those areas most critical to performance of health care professionals, such as the ability to obtain/interpret data, problem-solve, teach, communicate, and handle unpredictable patient behaviour. Traditional clinical examination basically tests a narrow range of clinical skills under the observation of normally two examiners in a given clinical case in form of patient histories, demonstration of physical examinations, and assessment of a narrow range of technical skills, unreliable in testing students. An OSCE approach has been used in assessing different aspects of obstetrics and gynaecology (McFaul, Taylor, \& Howie 1993) worldwide. For logistic reasons, many medical schools worldwide have modified the OSCE to appropriately suit their local needs.

\subsection{Initiation of OSCE as Problem Resolution}

The Department of Obstetrics and Gynaecology, Faculty of Medicine, Kuwait University, first implemented the Objective Structured Clinical Examination (OSCE) in the final examinations during the 2002-2003 academic years to replace the clinical examination with long case and short cases as the clinical component of the final examination in obstetrics and gynaecology

Despite increasingly widespread use of OSCEs, debate continues with arguments as "why using such a demanding format if other methods are available?" (Zayyan, 2014). There have been a number of studies investigating attitude of students and staff as a critique of different components of OSCE (Hammann et al., 2002; Hammad et al., 2013; Patrício et al., 2013; Nazeri astaneh et al., 2014; Zayyan, 2014; Duke et al., 2015). Moreover, the department is in the process of reviewing the utility of OSCE as a tool for evaluation of $6^{\text {th }}$ year medical students after their 12 week rotation in Obstetrics and Gynaecology. This is in keeping with the ongoing reforms in the student based curriculum that has been used for the past 15 years. 


\subsection{Objective of Study}

To evaluate the attitude and perception of medical students and academic staff towards OSCE as a method of clinical assessment in the in course and final examinations in Obstetrics and Gynaecology.

\section{Materials and Methods}

\subsection{Ethical Consideration}

The study was approved by the Institutional Review Board of the Maternity Hospital. Kuwait. Verbal informed consent was received from all women and to obtain the participants' informed consent, the objectives and general procedures of the research was explained to them as well as their right to drop out

\subsection{The Teaching Programme and Form of Assessment}

Teaching sessions are organized into limited didactic lectures and bedside teaching. Students learn skills by taking histories and performing physical examinations on selected patients, with emphasis on problem solving scenarios. Evaluation of the curriculum, teaching techniques and the course, were periodically discussed at departmental Council meetings. Until 2002, the in course and final clinical examinations included a long case in Obstetrics or Gynaecology and about five short cases.

\subsection{Developmental Framework of the OSCE}

Ten-OSCE-stations system was designed in 2002, pilot-tested at evaluation sessions and introduced into the student assessment system at the beginning of the 2002/2003 academic session in June, 2002. Following established methods, the course co-ordinator and a committee developed case scenarios, detailed instructions and checklists consisting of questions or tasks for 10 stations focused on specific clinical components of Obstetrics and Gynaecology. The main objective of the OSCE was to replace the long case and short cases, which together formed the clinical component of the final examination in Obstetrics and Gynaecology. The contents of the stations and the OSCE organization were refined through frequent discussions with all the academic staff members and through feedback from students and OSCE preceptors. The basic structure and operation of the OSCE are depicted in Figure 1, with two circuits of 12 stations each. Both circuits usually have similar questions;

\subsection{The OSCE Components}

The OSCE in our department encompasses 10 active and two rest stations in between of 10 minutes each. The examination is run in two parallel circuits conducted over 4 rotations with 20 - 30 minutes lunch break in between. The students in the morning and afternoon shifts are separately quarantined to avoid contacts and exchange of examination materials, adopts a broader perspective in which history taking, physical examination, practical skills, interpretation of results, and patient management are essentials of the OSCE. We make sure there is enough space for circuit running, to accommodate the various stations, equipment and materials for the exam. A station should accommodate an examiner, a student and the patient or standardised patient and also allow for enough privacy of discussion so that the students performing other tasks are not distracted or disturbed.

Each station usually has a set of instruments, imaging pictographs, surgical specimens, common drugs in Obstetrics and gynaecology, picture of a gynaecological or obstetric disorder and a simulated patient.

Most OSCEs use "standardized patients (SP)" for clinical history, Interpretation of laboratory and imaging results, treatment and counselling sessions. Standardized patients are individuals who have been trained to exhibit certain signs and symptoms of specific conditions under certain testing conditions. An advantage of simulated patients over real patients is that of allowing different candidates to be presented with a similar challenge, thereby reducing an important source of variability, reliable availability and adaptability, which enables the reproduction of a wide range of clinical phenomena tailored to the student's level of skill. They can simulate scenarios that may be distressing for a real patient, such as bereavement or terminal illness and thus removing the risk of injury or litigation while using real patients for examination especially in sensitive area of medicine like obstetrics and gynaecology. As shown in Table 1, about 2 to 3 months before the final examinations a blueprint is developed by the Examination Committee of the Department, to encompass areas of the curriculum from which the 10 stations are developed and distributed to the academic staff to prepare relevant questions, format of 
model answers and mark weightage. A month before the examination, there is a meeting of the Examination Committee to collate and edit the questions and finalize the details of the examination. Performance during the OSCE is judged by two or three examiners in each of the various stations of the examination.

\subsection{Evaluation of the Attitude and Perception of Students and Academic Staff}

Three groups were evaluated: 1) 96 medical students out of 140 (68.6\%) at the end of their rotation in Obstetrics and Gynaecology and the OSCE examination 2) 16 academic staff members (including 6 clinical tutors directly involved in the operation of the OSCE, 3) 30 resident doctors out of 38 (79\%) at the Maternity Hospital. The evaluation used a 14-point open-ended questionnaire with a 5-point numerical scale from 1 (very unsatisfactory)

\section{Organizational set up}

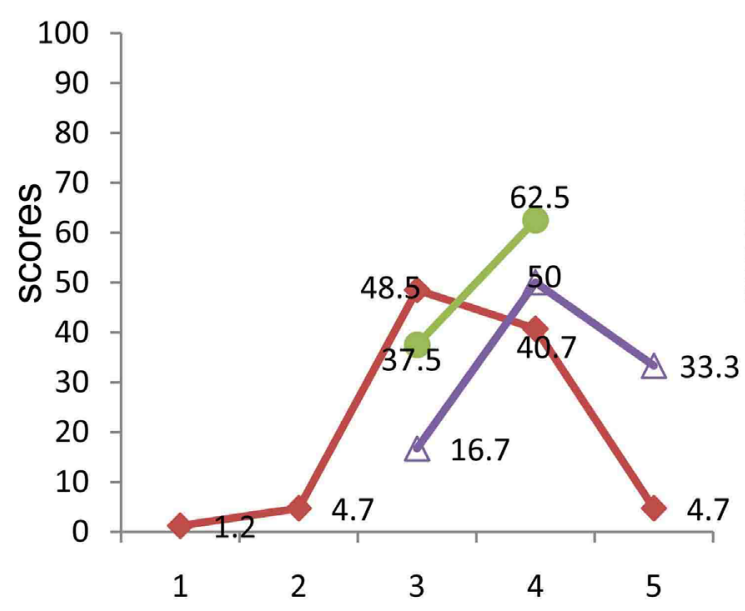

3. Examination environment

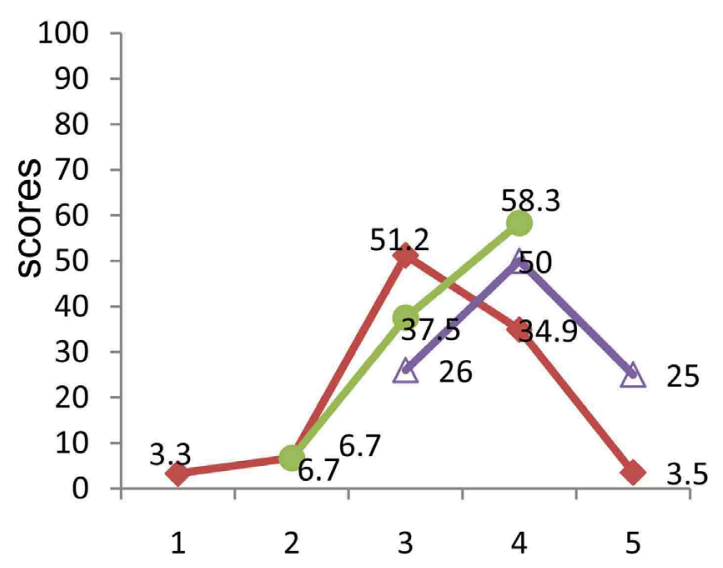

\section{Examination Instructions}

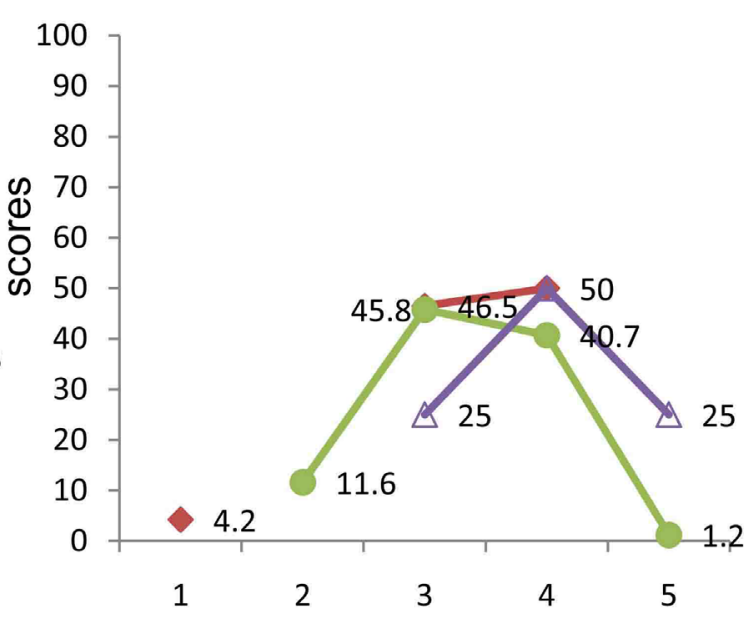

\section{Suitability of materials}

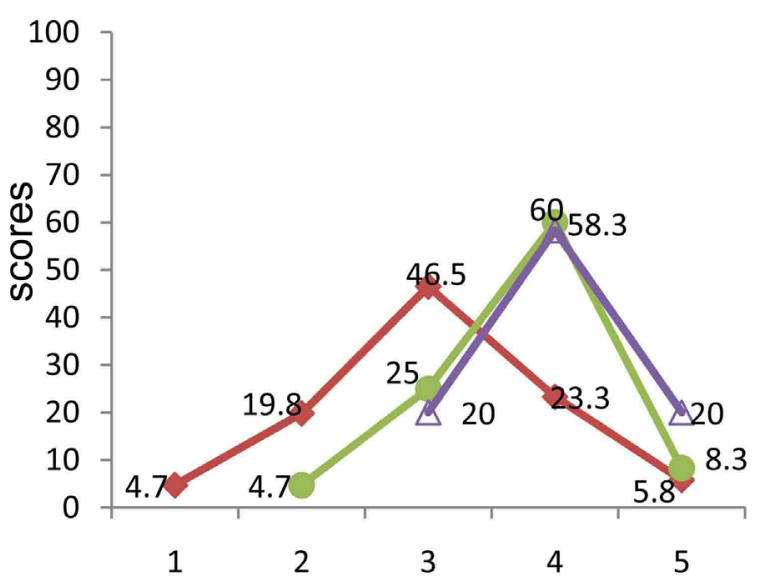

1 = Very unsatisfactory; 2 = Unsatisfactory; 3 = Satisfactory; 4 = Very Satisfactory; 5 = Outstanding

- Students' score; $\bullet$ Resident Scores; $\Delta$ Staff scores

- Students' Perception

Resident Doctors' Perception

$\triangle$ Academic Staff's Perception

(a) 
1. Evaluation of clinical skills

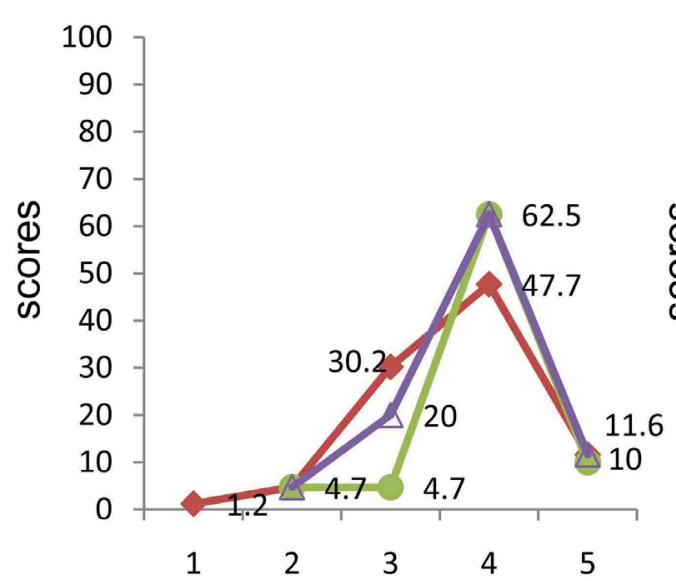

3. Evaluation of knowledge

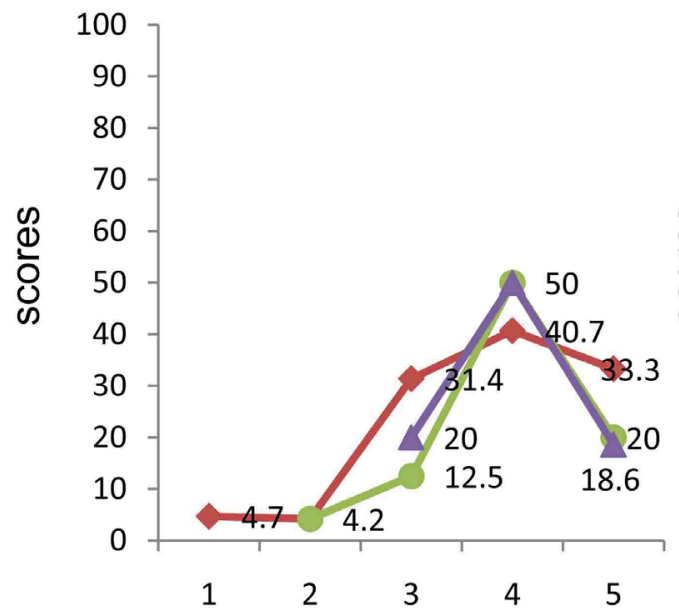

\section{Communication skills}

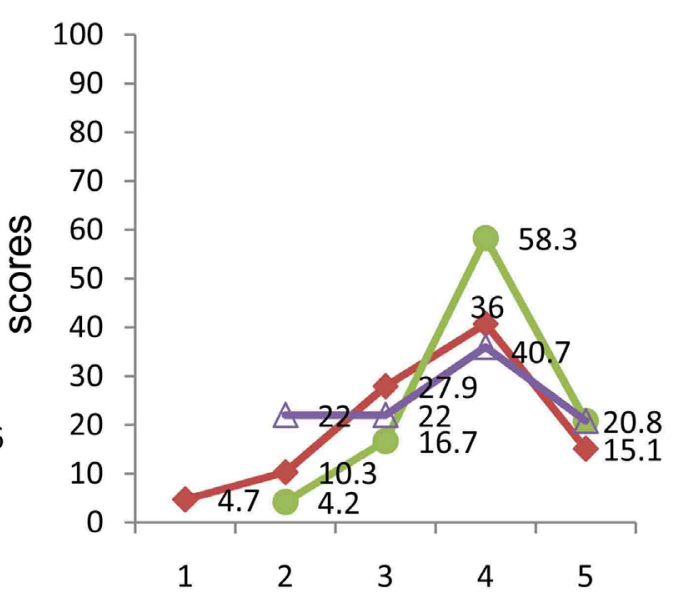

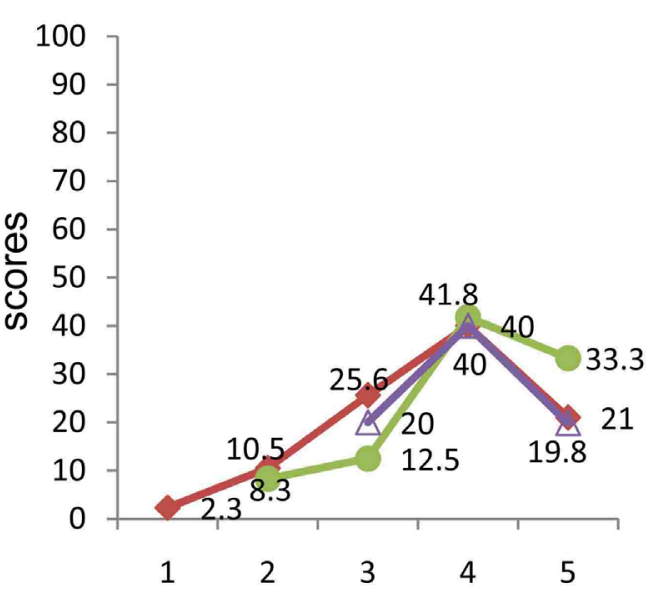

1 = Very unsatisfactory; 2 = Unsatisfactory; $3=$ Satisfactory; $4=$ Very Satisfactory; $5=$ Outstanding

- Students' score; $\bullet$ Resident Scores; $\Delta$ Staff scores

- Students' Perception

- Resident Doctors' Perception

$\triangle$ Academic Staff's Perception

(b)

Figure 1. Differential comparison of perception of OSCE by students, residents and academic staff.

to 5 (outstanding), with regards to their perception of examination attributes and usefulness of the OSCE, with regards to the organization, instruments of student's assessment, reliability and future developments. Score of 3 or more was accepted as a positive response.

\section{Statistical Analysis}

Closed questionnaire was analyzed in SPSS. Data were presented as percentage responses. Nonparametric analysis (Mann Whitney U test) was used to compare groups. A P value of less than 0.05 was considered significant. Spearman coefficient was used to assess the degree of reliability of students' Perception and attitude to OSCE. 
Table 1. Blueprint past OSCE in a typical academic year.

\begin{tabular}{cr}
\hline 1. & Pregnancy induced hypertension-Observed History Simulated patient \\
2. & Pelvic Abdominal Mass-Abdominal Examination \\
3. & Diabetes in Pregnancy-Preconception Counselling \\
4. & Intrauterine Fetal death/Breaking bad news \\
5. & Laparoscopic Sterilization (preparation for informed Consent) \\
6. & Dremature Ovarian Failure (Observed history in simulated patient \\
7. & Polyhydramnios (Abdominal Examination) \\
8. & Ovarian Torsion (Emergency management) \\
9. &
\end{tabular}

\section{Results and Interpretations}

The perception of OSCE as a replacement of the long case and short cases in the final examination in Obstetrics and Gynaecology was highly positive among the students, trainees and academic staff. As shown in Table 2, the three study groups approved of the organisational set-up and environment of the OSCE with a high score of 96\% and $94 \%$ respectively, clarity of instructions $81 \%$ and quality of examination materials $94 \%$ and there were no significant differences between the three study groups. In a similar fashion, the evaluation of acquired skills revealed a high degree of perception of OSCE as a method of assessing clinical skills (94\%), communication skills (84\%), patient care (84\%) and assessment of knowledge (91\%). The evaluation of reliability of OSCE was in response to the central objective of the replacement of the long case and short cases. The transparency of the process or lack of bias was ascertained to be high (90\%), objective (90\%) and the questions were related to the course thought (83\%). Evaluation of general issues of future perspectives revealed very interesting perception and differences between the three study groups. Although it was generally agreed that the OSCE was more expensive to run (76\%) and more labour intensive (86\%), there was significant divergence of opinion among staff and students (96\% versus 76, $P<0.05$ ). The clinical setting in the Maternity Hospital was less favoured by the students than staff with scores of $60 \%$ versus $96 \% ; P<0.02$ ).

\subsection{Divergence of Perception of OSCE}

Further analysis of the divergence of perception of OSCE by the three study groups are summarised in Figure 1(a) and Figure 1(b). The mean scores were superimposed in the construct. Although the students demonstrated a high degree of acceptance of the OSCE, their mean scores were invariably less than those of the resident doctors and academic staff $(P<0.05)$, except in evaluation of skills where there was complimentary overlap and uniformity with regards to clinical and communication skills, knowledge and transparency. In Figure 2, there is agreement about the objectivity of the OSCE and that it covered the course. However, 55\% of the students rejected the inclusion of the long case into the OSCE format compared to $15 \%$ of the staff $(P<0.01)$. In Table 3 , the Spearman coefficient was used to gauge the degree of favourability of domains of by the medical students. It obvious that OSCE was viewed by the students as being fair to all students, good method of evaluating clinical skills, reduction of examiners' bias and good replacement of the old system of long and short cases $(P<0.001)$ compared to staff. Next to secure the acceptance of the students was the adequate inclusion of questions from the course content $(P<0 / 01)$ and less significant was the lack of fear of confrontation with examiners $(P<0.05)$. The students were not in agreement with the assertion that OSCE was less stressful to the students and that there was less students and examiners' fatigue.

\subsection{Advantages and Disadvantages of OSCE}

Table 4 summarizes the perception of advantages of OSCE that were articulated by the three evaluating groups. The positive evaluation was consistent with the perception in Table 2 and Table 3 . All the three groups agreed that unlike the old system, OSCE was fair to all students because all students undergo same evaluation, with minimal examiners' bias. In addition, OSCE was a good method of evaluating clinical skills and associated with 
Table 2. Perception of different aspects of objective structured clinical examination (\%).

\begin{tabular}{|c|c|c|c|}
\hline Variable & Students $(\mathrm{n}=96)$ & Resident doctors $(n=30)$ & Academic staff $(n=18)$ \\
\hline \multicolumn{4}{|l|}{ Organization } \\
\hline Set up & $90(94)$ & $30(100)$ & $17(94)$ \\
\hline Environment & $89(93)$ & $29(97)$ & $17(94)$ \\
\hline Instructions & $84(88)$ & $29(97)$ & $16(89)$ \\
\hline \multicolumn{4}{|l|}{ Evaluation of skills } \\
\hline Communication & $84(88)$ & $27(79)$ & $15(83)$ \\
\hline Patient's care & $81(84)$ & $28(93)$ & $16(89)$ \\
\hline \multicolumn{4}{|l|}{ Reliability } \\
\hline Unbiased & $83(87)$ & $27(92)$ & $16(89)$ \\
\hline Objective & $86(90)$ & $26(87)$ & $16(89)$ \\
\hline Course related & $77(80)$ & $26(87)$ & $15(83)$ \\
\hline \multicolumn{4}{|l|}{ General issues } \\
\hline Expensive to run & $66(69)$ & $29(97)$ & $14(78)$ \\
\hline Labour intensive & $80(83)$ & $26(87)$ & $15(83)$ \\
\hline Good clinical setting & $52(54)$ & $23(73)$ & $11(61)$ \\
\hline
\end{tabular}

Table 3. Spearman correlation coefficient of students perception of OSCE.

\begin{tabular}{|c|c|c|c|c|c|c|c|c|c|c|}
\hline & 1 & 2 & 3 & 4 & 5 & 6 & 7 & 8 & 9 & 10 \\
\hline 1 & $0.814^{*}$ & & & & & & & & & \\
\hline 2 & $0.626^{* *}$ & $0.722^{* *}$ & & & & & & & & \\
\hline 3 & 0.094 & 0.048 & 0.112 & & & & & & & \\
\hline 4 & $0.388^{Y}$ & $0.378^{Y}$ & $0.342^{q}$ & 0.294 & & & & & & \\
\hline 5 & 0092 & 0.084 & 0.072 & 0.082 & 0.098 & & & & & \\
\hline 6 & $0.924^{*}$ & $0.846^{*}$ & 0.882 & $0.786^{*}$ & $0.892^{*}$ & $0.724^{* *}$ & & & & \\
\hline 7 & $0.944^{*}$ & $0.882 *$ & $0.884^{*}$ & $0.842^{*}$ & 0.862 & 0.882 & 0.878 & & & \\
\hline 8 & $0.824^{*}$ & $0.782^{*}$ & $0824^{*}$ & $0.782^{*}$ & $0.764^{*}$ & $0.824^{*}$ & $0.742^{*}$ & $0.794^{*}$ & & \\
\hline 9 & 0.262 & 0.234 & 0.238 & 0.224 & 0.242 & 0.238 & 0.236 & 0.232 & 0.238 & \\
\hline 10 & 0.124 & 0.142 & 0.084 & 0.164 & 0.142 & 0.186 & 0.178 & 0.164 & 0.188 & 0.214 \\
\hline
\end{tabular}

1 = Fair to all students ${ }^{*} ; 2$ = Included variety of questions from the course content ${ }^{* *} ; 3$ = Less stressful to the students; $4=$ No fear of confrontation with examiners ${ }^{*} ; 5=$ Systemic and easy to follow; $6=$ Good method of evaluating clinical skills ${ }^{*} ; 7=$ Reduced examiners' bias ${ }^{*} ; 8=$ Good replace- $^{*}$ ment for old system of long and short cases ${ }^{*} ; 9=$ Less examiners' fatigue; $10=$ Less students' fatigue. Spearman' correlation coefficient $\geq 0.300, P<$ $0.05 .{ }^{*} P<0.001 .{ }^{* *} P<0.01$. ${ }^{\sharp} P<0.05$.

adequate inclusion of questions from the course content. There was however, divergence of opinion about lack of fear of confrontation with examiners by students and less fatigue by students and staff $(P<0.05, P<0.01)$. As shown in Table 5, there was expression of some disadvantages of the OSCE. There was consensus that the rest stations were not enough and that under examination condition, it was unfair to start the examination with a rest station. More of the staff held the view that clinical problems and real patients were not enough $(P<0.05)$. The academic staff felt strongly that the staff involved in the running of the OSCE was inadequate. Distraction by the change-over bell, lack of body language by the simulated patients and lack of clarity of the instructions in 

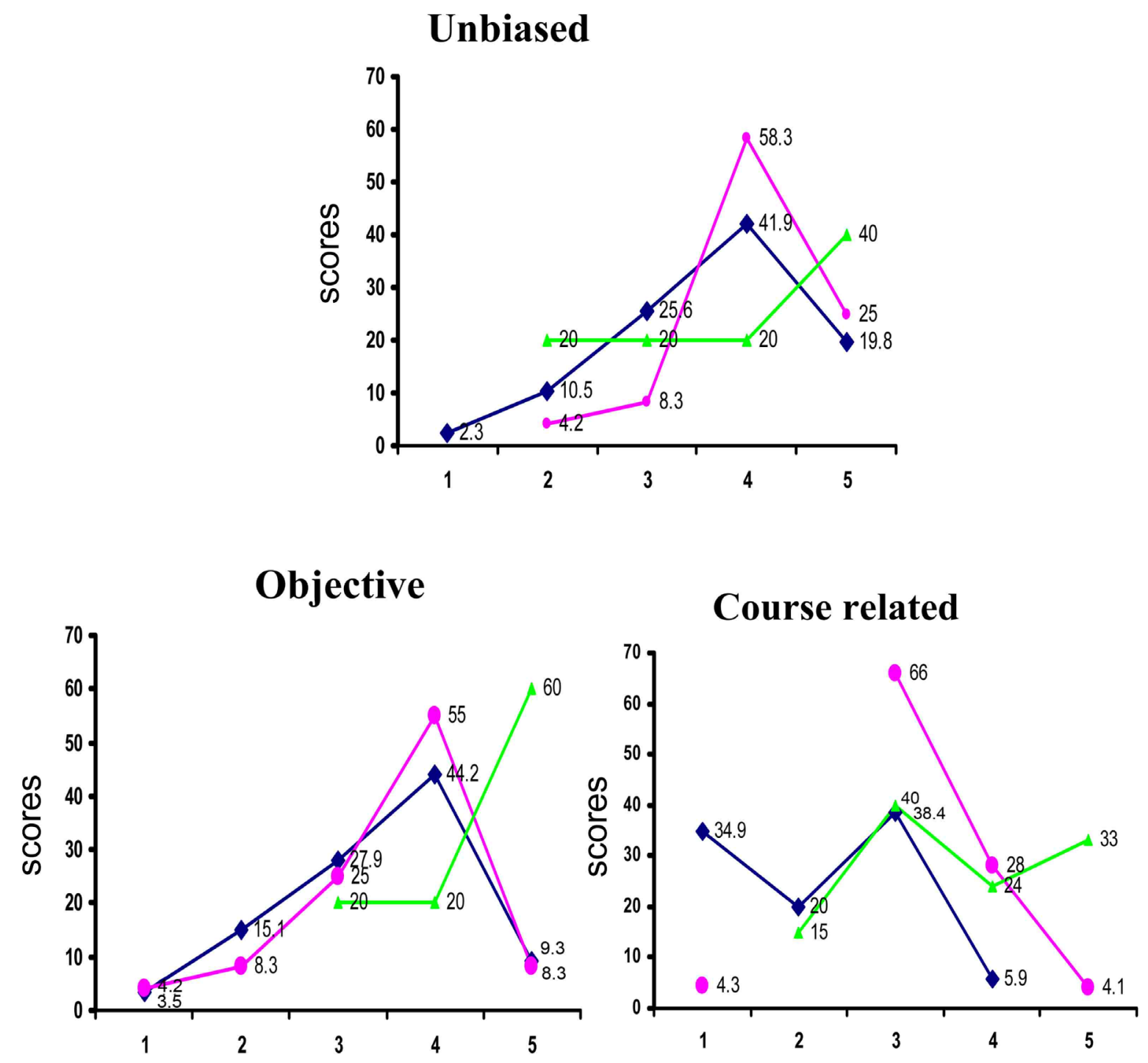

1 = Very unsatisfactory; 2 = Unsatisfactory; 3 = Satisfactory; 4 = Very Satisfactory; 5 = Outstanding

Students' Perception

Resident Doctors' Perception

Academic Staff's Perception

Figure 2. Analysis of reliability of OSCE by students, trainees and academic staff.

some stations were mainly highlighted by the students.

\section{Discussion}

\subsection{OSCE Germinates Fairness}

In the present study, both students and faculty are in agreement that the OSCE represented an appropriate and fair evaluation method in the final MB, B.Ch examinations in Obstetrics and Gynaecology as a replacement of the long and short cases of the old curriculum. It is designed to test clinical skill performance and competence in skills such as communication, clinical examination, medical procedures/prescription, exercise prescription, joint mobilisation/manipulation techniques, radiographic positioning, radiographic image evaluation and interpretation of results, as has been previously described (Patrício et al., 2013). The present study has shown that there are many advantages of the OSCE over the traditional clinical examinations. Firstly, as has been clearly demon- 
Table 4. Advantages of objective structured clinical examination (OSCE).

\begin{tabular}{cccc}
\hline Variable & Students (n = 96) & Resident doctors (n = 30) & Academic staff \\
\hline Fair to all students in the class & $84(88 \%)$ & $28(98 \%)$ & $18(100 \%)$ \\
All students undergo the same evaluation & $96(100 \%)$ & $30(100 \%)$ & $18(100 \%)$ \\
Variety of topics from the course included & $68(71 \%)$ & $24(80 \%)$ & $18(100 \%)$ \\
Less stressful to the students & $54(56 \%)$ & $18(80 \%)$ & $16(89 \%)$ \\
No fear of confrontation with examiners & $44(46 \%)$ & $16(83 \%)$ & $18(100 \%)$ \\
Systematic and easy to follow & $64(67)$ & $30(100 \%)$ & $18(100 \%)$ \\
Good method of evaluating clinical skills & $92(96 \%)$ & $28(93 \%)$ & $16(89 \%)$ \\
No examiners' bias & $84(88 \%)$ & $24(80 \%)$ & $18(100 \%)$ \\
Good replacement for long and short cases & $68(71 \%)$ & $24(80 \%)$ & $14(78 \%)$ \\
Less examiners' fatigue & $22(23 \%)$ & $28(93 \%)$ & $14(78 \%)$ \\
Covers the whole course & $48(50 \%)$ & & $18 \%$ \\
\hline
\end{tabular}

Table 5. Disadvantages of objective structured clinical examination.

\begin{tabular}{cccc}
\hline Variables & $\begin{array}{c}\text { Medical students } \\
(\mathbf{n}=\mathbf{9 6})\end{array}$ & $\begin{array}{c}\text { Resident doctors } \\
(\mathbf{n}=\mathbf{3 0})\end{array}$ & $\begin{array}{c}\text { Academic staff } \\
(\mathbf{n}=\mathbf{1 8})\end{array}$ \\
\hline Clinical problems not enough & $6(6.3 \%)$ & $2(6.7 \%)$ & $6(33.3 \%)$ \\
Not enough Rest stations & $18(18.8 \%)$ & $4(13.3 \%)$ & $4(22.2 \%)$ \\
Not enough time for a station & $40(41.7 \%)$ & $2(6.7 \%)$ & $2(11.1 \%)$ \\
Patient-station not enough & $6(6.3 \%)$ & $2(6.7 \%)$ & $6(33.3 \%)$ \\
Some station-pictures not clear & $18(18.8 \%)$ & $3(10.0 \%)$ & $2(11.1 \%)$ \\
Unfair to start with Rest station & $34(35.4 \%)$ & $12(40.0 \%)$ & $14(74.4 \%)$ \\
Lack of adequate body language in simulated patient & $40(41.7 \%)$ & $14(46.7 \%)$ & $12(66.7 \%)$ \\
Not suitable for long case & $2(2.1 \%)$ & $22(73.3 \%)$ & $16(88.9 \%)$ \\
Not enough staff & $24(25 \%)$ & $12(40.0 \%)$ & $4(22.2 \%)$ \\
Distract by change-over bell & $32(33.3 \%)$ & $2(6.7 \%)$ & $2(11.1 \%)$ \\
Some questions not clear & $24(25 \%)$ & $8(26.7 \%)$ &
\end{tabular}

strated by Students and staff in the present study, the OSCE is fairer than the traditional approach due to the standardisation of tasks that have to be performed, an aspect much appreciated by students. Other advantages of OSCE include versatility, broadened scope, objectivity, reproducibility, and easy recall. All students get examined on predetermined criteria on same or similar clinical scenario or tasks with marks written down against those criteria thus enabling recall, teaching audit and determination of standards, allows for review of teaching technique and curricula (Zayyan, 2014). Secondly, the wider sampling of competencies and the use of structured marking sheets contribute to improvements in reliability and content validity (Hammann et al. 2002). This practice is adopted worldwide (Newble \& Dawson 1994; Stillman et al., 1997; Descargues et al., 2001; Furmedge et al., 2016).

\subsection{Validity and Reliability of OSCE}

Published findings on OSCE from its inception in 1975 to 2015 have reported it to be reliable, valid and objective with cost as its only major drawback. The OSCE covers broader range like problem solving, communication skills, decision-making and patient management abilities (Harden et al., 1975; Hamad, Oweis, \& Taha, 2013; Patrício et al., 2013; Nazeri astaneh et al., 2014). Many Obstetrics and Gynaecology establishments have embraced the use of OSCE in the assessment of clinical competencies of medical students to good effect (Grand' 
Maison, Blouin, \& Brerie, 1985; McFaul, Taylor, \& Howie 1993; Hodges et al., 1998; Descargues et al., 2001). We have used the OSCE to replace the long and short cases with emphasis on clinical data interpretation, clinical and communication skills and patient care, complementing traditional evaluations of knowledge that use the long case, written multiple choice questions and essay questions. Others have examined the use of different examination personnel as examiners or patients, compared to students' course feedback to their OSCE performance, examined costs or reliability and generalizability, compared to training locations or provided general descriptions of their OSCEs (Stillman et al., 1997; Duffield \& Spencer, 2002). OSCE has been used to examine how well second-year students learn clinical skills in the second-year physical diagnosis course at Harvard Medical School). An important advantage of OSCE is that comprehensive investigation is likely to help determine what aspects of the educational process that should be improved. According to Wallace et al. (2002) the idealised "textbook" scenarios may not mimic real-life situations and may not allow assessment of complex skills.

\subsection{Cost-Benefit Analysis of OSCE}

The present study has shown that OSCE is expensive in terms of manpower requirement and labour intensive, stressful to the students with associated fatigue to both students and staff. There is cost involvement in financial expenditure, personnel and training issues in setting up the stations. With 10 stations in two circuit running concurrently, at least 40 examiners are required with at least 20 trained simulated patients and a good number of support staff. There is evidence that the use of one examiner in one station has been found to result in good reliability (Zayyan, 2014). The main purpose of the OSCE is to improve the quality of care provided to the community by graduating medical students. Exploring the attitude and perception of students towards the OSCE is sacrosanct. In the present study, the students gave their absolute approval towards the continued use of OSCE for final clinical. This would highlight the need for student participation in the development of new assessment tools in medical curricula, as their acceptance will be more favourable for assessment formats that they perceive to be transparent, authentic and valid. Traditional medical curricula must be responsive to global paradigm shifts in undergraduate medical education (Allen et al., 1998; Duffield \& Spencer, 2002; Pierre et al., 2004; Nalesnik et al., 2005; Brannick et al., 2011; Raheel \& Naem, 2013). The clinical examination in Obstetrics and Gynaecology in our establishment used to cover four days. With OSCE, the examination covers one full day. The perceived stress and fatigue to students and staff pales in comparison to previous four days of clinical examination.

\subsection{Need for Developmental Improvement}

The validity and reliability of OSCE evaluation have been reported with controversial results (Walter, Osborn, \& Raven 2005; Patrício et al., 2013). Better than average reliability was associated with a greater number of stations and a higher number of examiners per station. Interpersonal skills were evaluated less reliably across stations and more reliably within stations compared with clinical skills. It is more difficult to reliably assess communication skills than clinical skills when considering both as general traits that should apply across situations (Patrício et al., 2013). It has been suggested that it is helpful to use two examiners and large numbers of stations, but some OSCEs appear more reliable than others for reasons that are not yet fully understood) and the type of patients represented and the format of the examination itself, including the length of the examination, the number and duration of stations (Allen et al., 1998; Duffield \& Spencer, 2002; Nalesnik et al., 2005; Walter et al., 2005; Patrício et al., 2013) all contribute to the validity and reliability of OSCE as a tool for evaluation in final examinations.

\section{Future Directions}

Adequate training of simulated patients before use in OSCE is mandatory. Examiner selection with prior training in the tenets and format of OSCE is significant. Validity and reliability areas need continuing research in all the domains of OSCE. Student feedback should be necessary after each examination. This would help to refine and distill the system and improve the outcome (Allen et al. Missing link in the programme is clinical thinking. It is one of the core competencies in medical education, which plays a major role in the ability of doctors to make a diagnosis and make treatment decisions (Smith, 2008, Michels, Evans, \& Blok, 2012; Sim et al., 2015). As the process of globalization is increasingly evident in medical education, OSCE should be developed with the concept of global minimum essential requirements in medical education (The Institute for International 
Medical Education, 2002).

\section{Limitations of the Study}

The present study involved a small sample size limited to one academic session. Future study should involve a larger sample size and many years of use of OSCE, and should include evaluation of students' performance from one station to the other.

\section{Conclusion}

Based on examinees 'attitudes, OSCE may be a more appropriate choice for graduation examinations of compared to the conventional clinical examination. It is expensive in terms of manpower requirement. There should be continuing research to find strategies to reduce cost stress to students and examiners. Validity and reliability of the whole OSC and the different stations should be veritable areas of research to further improve the outcome of OSCE as an evaluation tool.

\section{Acknowledgements}

The authors wish to express profound gratitude to the Dean and staff of Faculty of Medicine, Kuwait University for nurturing our departmental vision of universality of medical education. The technical staff of Department of Obstetrics and Gynecology, Faculty of Medicine, Kuwait University who contributed immensely with the statistical analysis deserved exceeding gratitude. The study was partially supported by Grant MO360 of the Research Sector, Kuwait University, Kuwait

\section{References}

Allen, R., Heard, J., Savidge, M., Bittengle, J., Cantrell, M., \& Huffmaster, T. (1998). Surveying Students’ Attitudes during the OSCE. Advances in Health Sciences Education, 3, 197-206. http://dx.doi.org/10.1023/A:1009796201104

Brannick, M. T., Erol-Korkmaz, H. T., \& Prewett, M. (2011). A Systematic Review of the Reliability of Objective Structured Clinical Examination Scores. Medical Education, 45, 1181-1189. http://dx.doi.org/10.1111/j.1365-2923.2011.04075.x

Carraccio, C., \& Englander, R. (2000). The Objective Structured Clinical Examination. A Step in the Direction of Competency-Based Evaluation. Archives of Pediatrics and Adolescent Medicine, 154, 736-741.

http://dx.doi.org/10.1001/archpedi.154.7.736

Descargues, G., Sibert, L., Lechevallier, J., Weber, J., Lemoine, J. P., \& Marpeau, L. (2001). Evaluation of Clinical Competence in Gynecology Obstetrics: An Innovative Approach Using the Objective Structured Clinical Examination. Journal de Gynécologie Obstétrique et Biologie de la Reproduction (Paris), 30, 257-264. French.

Duffield, K. E., \& Spencer, J. A. (2002). A Survey of Medical Students’ Views about the Purposes and Fairness of Assessment. Medical Education, 36, 879-886. http://dx.doi.org/10.1046/j.1365-2923.2002.01291.X

Duke, E. U., Mgbekem, M. A., Nsemo, A. D., Ojong-Alacia, M. M., Nkwonta Chigozie, A., \& Mobolaji-Olajide, O. M, (2015). Influence of Marital Status on Attitude of Midwives towards OSCE and Their Performance in the Examination in Akwa Ibom and Cross River States. Nigeria Journal of Education and Training Studies, 3, 2324-8068.

Furmedge, D. S., Smith, L.-J., \& Sturrock, A. (2016). Developing Doctors: What Are the Attitudes and Perceptions of Year 1 and 2 Medical Students towards a New Integrated Formative Objective Structured Clinical Examination? BMC Medical Education, 16, 32.

Grand'Maison, P., Blouin, D., \& Briere, D. (1985). Utilization of the Objective Structured Clinical Examination (OSCE) in Gynecology/Obstetrics. Proceedings of the Annual Conference on Research in Medical Education, 24, 65-70.

Hammad, M., Oweis, Y., Taha, S., Hattar, S., Madarati, A., \& Kadim, F. (2013). Students’ Opinions and Attitudes after Performing a Dental OSCE for the First Time: A Jordanian Experience. International Dental Education, 77, 99-104.

Hammann, C., Volkan, K., Fishman, M. B., Simon, S. R., \& Fletcher, S. W. (2002). How Well Do Second-Year Students Learn Physical Diagnosis? Observational Study of an Objective Structured Clinical Examination (OSCE). BMC Medical Education, 2, 1. http://dx.doi.org/10.1186/1472-6920-2-1

Harden, R. M., Stevenson, M., Downy, W. W., \& Wilson, G. M. (1975). Assessment of Clinical Competence Using Objective Structured Examination. British Medical Journal, 1, 447-451. http://dx.doi.org/10.1136/bmj.1.5955.447

Hodges, B., Regehr, G., Hanson, M. et al. (1998). Validation of an Objective Structured Clinical Examination in Psychiatry. Academic Medicine, 73, 910-912. http://dx.doi.org/10.1097/00001888-199808000-00019 
McFaul, P. B., Taylor, D. J., \& Howie, P. W. (1993). The Assessment of Clinical Competence in Obstetrics and Gynaecology in Two Medical Schools by an Objective Structured Clinical Examination. British Journal of Obstetrics and Gynaecology, 100, 842-846. http://dx.doi.org/10.1111/j.1471-0528.1993.tb14311.x

Michels, M. E., Evans, D. E., \& Blok, G. A. (2012). What Is A Clinical Skill? Searching for Order in Chaos through a Modified Delphi Process. Medical Teacher, 34, e573-e581. http://dx.doi.org/10.3109/0142159X.2012.669218

Nalesnik, S. W., Mills, C. S., Olsen, C. H., Haffner, W. H., \& Zahn, C. M. (2005). Creating an Ideal Objective Structured Clinical Exam for an Obstetrics and Gynecology Medical Student Clerkship. American Journal of Obstetrics \& Gynecology, 193, 1544-1550. http://dx.doi.org/10.1016/j.ajog.2005.06.067

Nazeri astaneh, A., Mirabzadeh, A., Karimloo, M., Rezae, I. O., Fadai, F. , Alibeigi, N., Mazinani, R., Samiei, M., \& Khodaei, M. R. (2014). Investigating the Attitude of Graduate Psychiatrists towards Objective Structured Clinical Examination (OSCE) and Conventional Clinical Interview Examination. Iranian Journal of Psychiatry, 9, 110-114.

Newble, D., Dawson, B. et al. (1994). Guidelines for Assessing Clinical Competence. Teaching and Learning in Medicine, 6 , 213-220.

Patrício, M. F., Julião, M., Fareleira, F., \& Carneiro, A. V. (2013). Is the OSCE a Feasible Tool to Assess Competencies in Undergraduate Medical Education? Medical Teacher, 35, 503-514. http://dx.doi.org/10.3109/0142159X.2013.774330

Pierre, R. B., Wierenga, A., Barton, M., Branday, J. M., \& Christie, C. D. C. (2004). Student Evaluation of an OSCE in Paediatrics at the University of the West Indies, Jamaica. BMC Medical Education, BMC Series, 4, 22. http://dx.doi.org/10.1186/1472-6920-4-22

Raheel, H., \& Naeem, N. (2013). Assessing the Objective Structured Clinical Examination: Saudi Family Medicine Undergraduate Medical Students' Perceptions of the Tool. Juvenile Products Manufacturers Association, 63, 1281-1284.

Sim, J. H., Aziz, Y. F. A., Mansor, A., Vijayananthan, A., Foong, C. C., \& Vadivel, J. (2015). Students’ Performance in the Different Clinical Skills Assessed in OSCE: What Does It Reveal? Medical Education Online, 20, 26185.

Smith, C. S. (2008). A Developmental Approach to Evaluating Competence in Clinical Reasoning. Journal of Veterinary Medical Education, 35, 375-381. http://dx.doi.org/10.3138/jvme.35.3.375

Stillman, P. L., Wang, Y., Ouyang, Q., Zhang, S., Yang, Y., \& Sawyer, W. D. (1997). Teaching and Assessing Clinical Skills: A Competency-Based Programme in China. Medical Education, 31, 33-40. http://dx.doi.org/10.1111/j.1365-2923.1997.tb00040.x

The Institute for International Medical Education (IIME) (2002). Global Minimum Essential Requirements in Medical Education. Medical Teacher, 24, 130-135. http://dx.doi.org/10.1080/01421590220120731

Wallace, J., Rao, R., \& Haslam, R. (2002). Simulated Patients and Objective Structured Clinical Examinations: Review of Their Use in Medical Education. Advances in Psychiatric Treatment, 8, 342-348. http://dx.doi.org/10.1192/apt.8.5.342

Walters, K., Osborn, D., \& Raven, P. (2005). The Development, Validity and Reliability of a Multimodality Objective Structured Clinical Examination in Psychiatry. Medical Education, 39, 292-298. http://dx.doi.org/10.1111/j.1365-2929.2005.02091.x

Zayyan, M. (2014). Objective Structured Clinical Examination: The Assessment of Choice. Oman Medical Journal, 26, 219222. 